Original Article

\title{
Is there a difference in the electromyographic activity of the pelvic floor muscles across the phases of the menstrual cycle?
}

\author{
Maria Thereza Micussi, PhD ${ }^{1)^{*}}$, Rodrigo Pegado Freitas ${ }^{1)}$, Priscylla Helouyse Angelo ${ }^{1)}$, \\ Elvira Maria Soares, PhD $^{2)}$, Telma Maria Lemos, PhD ${ }^{3)}$, Técia Maria Maranhão, $P_{h}^{4}{ }^{4}$ \\ 1) Department of Physiotherapy, Universidade Federal do Rio Grande do Norte: Av. Salgado Filho, \\ 3000, Lagoa Nova. Natal- RN, 59078-970, Brazil \\ 2) Maternidade-Escola Januário Cicco, Universidade Federal do Rio Grande do Norte, Brazil \\ 3) Department of Clinical Analysis, Universidade Federal do Rio Grande do Norte, Brazil \\ 4) Department of Tocogynecology, Universidade Federal do Rio Grande do Norte, Brazil
}

\begin{abstract}
Purpose] To evaluate the electrical activity of the pelvic floor muscle in women during the follicular, ovulatory, and luteal phases of the menstrual cycle and its correlation with estradiol and total testosterone levels. [Subjects and Methods] This cross-sectional study involved 30 women with ovulatory menstrual cycles. Total testosterone and estradiol levels were measured and the muscle tone and maximum voluntary contraction of the pelvic floor muscles were evaluated using surface electromyography. [Results] Muscle tone was significantly lower during the follicular $(21.1 \pm 3.3 \mu \mathrm{V})$ and ovulatory $(27.1 \pm 5.9 \mu \mathrm{V})$ phases than the luteal phase $(30.4 \pm 4.1 \mu \mathrm{V})$. The maximum voluntary contraction was not different across phases. The estradiol level on the 7th day of the menstrual cycle showed a strong positive correlation with muscle tone and maximum voluntary contraction, and the testosterone level was positively correlated with muscle tone on the 21st day. [Conclusion] Women have better muscle tone during the luteal phase. The muscle tone and maximum voluntary contraction were strongly correlated with the estradiol level on the 7th day, and the muscle tone was correlated with the testosterone level on the 21st day of the menstrual cycle. These findings suggest that hormonal fluctuations during the menstrual cycle alter pelvic floor muscle activity.

Key words: Electromyography, Pelvic floor, Menstrual cycle
\end{abstract}

(This article was submitted Feb. 25, 2015, and was accepted Apr. 13, 2015)

\section{INTRODUCTION}

In women, the menstrual cycle occurs every month between puberty and menopause. This cycle involves complex and periodic changes in the female anatomy and physiology, characterized by follicular development, ovulation, and the formation and regression of the corpus luteum. It is well recognized that during the follicular phase of the menstrual cycle estrogen levels rise to a peak and then fall approximately 1-2 days before ovulation, while during the luteal phase the estrogen levels remain relatively stable but at a higher level than that at the start of the cycle. The regular pattern of the menstrual cycle is achieved through integration of the hypothalamic-pituitary-adrenal axis ${ }^{1)}$.

Previous studies suggest that the hormonal fluctuations of the menstrual cycle can alter the force and resistance

\section{*Corresponding author. Maria Thereza Micussi (E-mail:} therezamicussi@yahoo.com.br)

(C2015 The Society of Physical Therapy Science. Published by IPEC Inc. This is an open-access article distributed under the terms of the Creative Commons Attribution Non-Commercial No Derivatives (by-ncnd) License $<$ http://creativecommons.org/licenses/by-nc-nd/3.0/> . of the skeletal muscles, which occurs due to the presence of androgen and estrogen receptors that modulate skeletal muscle function according to hormone levels ${ }^{1,2)}$. In men, a direct association exists between testosterone and increases in muscle mass, volume, and maximum voluntary force; however, the action of testosterone on the skeletal muscles in women is not yet completely elucidated ${ }^{3,4)}$. However, it is known that the decline in estrogen levels, such as in the climacteric period, has been associated with weakness in the pelvic floor muscles (PFMs) and consequently the potential appearance of urogynecological dysfunction, such as urge incontinence ${ }^{5,6)}$.

The PFM comprises a set of skeletal muscles, with the levator ani muscle as the main structure, which is composed of the pubococcygeus, iliococcygeus, and puborectalis muscles $^{7)}$. Through static and dynamic control, these muscles are responsible for supporting the internal pelvic organs and for sphincter closure, enabling urinary and fecal continence ${ }^{5)}$. Moreover, this muscular complex has the capacity to neutralize excessive abdominal pressure, and these muscles are considered to be functioning properly when they are able to perform a voluntary muscular contraction and close the urethral and anal sphincters ${ }^{7,8)}$. Studies of muscle performance during the menstrual cycle have concentrated mainly 
on changes in endurance, rather than strength, and have not evaluated the force and tone of the PFMs $1,4,6,7)$. Perhaps women might experience differences in force and tone during the menstrual phases, causing a dynamic and cyclic muscle action condition. To understand dysfunction of the PFMs and improve the manner in which health professionals approach therapy, it is crucial to understand the muscle capacity during different phases of the normal menstrual cycle. Therefore, the purpose of this study was to evaluate the electrical activity of the PFMs in younger women during the follicular, ovulatory, and luteal phases, and to correlate this information with estradiol $\left(E_{2}\right)$ and total testosterone (TT) levels.

\section{SUBJECTS AND METHODS}

The methodological design was a cross-sectional analytical study. Thirty younger women with ovulatory menstrual cycles were recruited from the Maternity of the Federal University of Rio Grande do Norte (UFRN). Participants provided written informed consent, and the study was conducted in accordance with the principles of the Declaration of Helsinki. The study was approved by the Federal University of Rio Grande do Norte Research Ethics Committee.

The participants included were nulligravid women between 20 and 30 years of age with ovulatory menstrual cycles (26-32 days long), confirmed by a blood concentration of progesterone equal to or above $5 \mathrm{ng} / \mathrm{mL}$ on the $21 \mathrm{st}$ day of the cycle. The following exclusion criteria were applied: diabetes mellitus, any disease that causes chronic anovulation or hyperandrogenism (e.g., hyperprolactinemia, thyroid disturbances, congenital adrenal hyperplasia, Cushing's syndrome, polycystic ovary syndrome, and androgensecreting tumors of adrenal or ovarian origin), suspicion of or confirmed pregnancy, previous gynecological surgery, perineal rupture, body mass index (BMI) above $25 \mathrm{~kg} / \mathrm{m}^{2}$, and the use of any medication that might interfere with the HPA axis in the previous 90 days. All participants had no complaints of urinary or anal incontinence, and no patients had previous physiotherapy or performed personal Kegel exercises.

All patients provided a detailed medical history and underwent a physical exam and biochemical analysis, which included measuring their hormone levels. The medical history assessment collected data on the menarche, the character of the menstrual cycle (regular or irregular), and any personal or familial history of diabetes mellitus, cardiovascular disease, dyslipidemia, or obesity. The physical exam involved a gynecological evaluation to analyze the pelvic floor, cases of perineal rupture, and local inflammation. Height, weight, and the waist and hip circumferences were measured to calculate the BMI and waist-to-hip ratio. BMI was calculated as the weight $(\mathrm{kg})$ divided by the height squared $\left(\mathrm{m}^{2}\right)$ and was classified in accordance with criteria established by the World Health Organization ${ }^{9}$ : underweight BMI, $<18.5 \mathrm{~kg} /$ $\mathrm{m}^{2}$; normal weight BMI, $18.5-24.9 \mathrm{~kg} / \mathrm{m}^{2}$; overweight BMI, $25-29.9 \mathrm{~kg} / \mathrm{m}^{2}$; and obese BMI, $\geq 30 \mathrm{~kg} / \mathrm{m}^{2}$.

For the hormonal and biochemical analyses, blood samples were collected in the morning after an all night fast (at least 8 hours). Glycemia was determined by the glucose oxidase method. Levels of total cholesterol, high density lipoprotein cholesterol (HDL-C), triglycerides, aspartate aminotransferase, alanine aminotransferase, gamma-glutamyl transferase, urea, and creatinine were determined through enzymatic colorimetric assays (Biosystems, Barcelona, Spain). The low density lipoprotein (LDL) levels were determined using the Friedewald equation. The levels of $\mathrm{E}_{2}$, $\mathrm{TT}$, progesterone, and thyroid stimulating hormone (TSH) were determined through chemiluminescence analysis, using the appropriate kits (Diagnostic Products Corporation, Los Angeles, CA, USA) for the Immulite 2000 device.

During electromyography (EMG), each patient was asked to adopt the lithotomy position. An intracavity electrode (Chattanooga Group ${ }^{\circledR}$, USA) was inserted into the third portion of the vaginal canal, with metal plates positioned in contact with the lateral walls of the vagina. A reference electrode was positioned on the anterior superior iliac spine. Data were processed with EMG software (EMG System do Brasil Ltd. $\left.{ }^{\circledR}\right)$, with a band-pass frequency filter of 20 to $500 \mathrm{~Hz}$. Before the exam, the patient was taught how to contract the PFMs properly and was advised to empty her bladder. After the vaginal electrode was introduced, the patient was instructed to relax the pelvic floor for 10 seconds. The base muscle tone was recorded for 1 minute. Next, the patient performed three voluntary contractions of the PFMs, with an interval of 30 seconds between each contraction. The highest result of the three contractions was used as the maximum voluntary contraction (MVC) and expressed in microvolts $(\mu \mathrm{V})^{10)}$

Hormone levels were collected and the EMG exam was performed on the 7th day (follicular phase), 14th day (ovulatory phase), and 21 st day (luteal phase) of each patient's menstrual cycle. Progesterone was measured only on the 21 st day of the menstrual cycle to confirm ovulation.

The data obtained were tabulated using SPSS 19.0 software for Windows. The Shapiro-Wilk test was used to confirm that the data were normally distributed. Measurements of central tendency were used to describe the gynecological information and laboratory exam results. Electrical activity during the three phases of the menstrual cycle was analyzed using the Kruskall-Wallis test and Dunn post-test. The Spearman rank correlation coefficient $(r)$ was used to determine the correlation between EMG activity and hormone levels. Differences with a p-value less than 0.05 were considered statistically significant.

\section{RESULTS}

The mean age and menarche age were $27.2 \pm 4.4$ and $14.3 \pm 3.1$, respectively. The dosage of TSH was $1.44 \pm 0.8$ $\mu \mathrm{IU} / \mathrm{ml}$, and the mean serum level of progesterone on the $21 \mathrm{st}$ day was $11.8 \pm 3.5 \mathrm{ng} / \mathrm{ml}$. Table 1 displays the clinical and hormonal characteristics of the sample. Levels of $E_{2}$ and TT differed significantly across the different phases of the menstrual cycle (Table 2).

Muscle tone was significantly different between the follicular $(21.1 \pm 3.3 \mu \mathrm{V})$ and luteal $(30.4 \pm 4.1 \mu \mathrm{V})$ phases $(\mathrm{p}=0.01)$ and between the ovulatory $(27.1 \pm 5.9 \mu \mathrm{V})$ and luteal $(30.4 \pm 4.1 \mu \mathrm{V})$ phases $(\mathrm{p}<0.001)$. The MVC did not show any differences across the phases of the menstrual 
Table 1. Clinical and biochemical characteristics of the patients at the start of the evaluation

\begin{tabular}{lccc}
\hline Variable & Average & SD & Reference \\
\hline Age & 27.2 & \pm 4.4 & \\
Weight $(\mathrm{kg})$ & 51.8 & \pm 5.2 & \\
BMI & 20.9 & \pm 2.4 & $20.00-24.99$ \\
Waistline $(\mathrm{cm})$ & 73.4 & \pm 5.3 & \\
Hip line $(\mathrm{cm})$ & 91.2 & \pm 4.9 & \\
Waist-hip ratio & 0.80 & \pm 0.2 & \\
Fasting glucose (mg/dl) & 71.8 & \pm 4.1 & $70.00-99.00$ \\
Alanine aminotransferase (U/L) & 32.7 & \pm 3.4 & $0.00-31.00$ \\
Aspartate aminotransferase (U/L) & 33.4 & \pm 4.5 & $0.00-31.00$ \\
Creatinine (mg/dl) & 0.7 & \pm 0.2 & $0.40-1.40$ \\
Urea $(\mathrm{mg} / \mathrm{dl})$ & 18.5 & \pm 6.2 & $15.00-40.00$ \\
Total cholesterol $(\mathrm{mg} / \mathrm{dl})$ & 186.9 & \pm 25.7 & $<200$ \\
LDL (mg/dl) & 83.7 & \pm 17.2 & $<100$ \\
HDL $(\mathrm{mg} / \mathrm{dl})$ & 67.3 & \pm 15.8 & $\geq 60$ \\
Triglycerides $(\mathrm{mg} / \mathrm{dl})$ & 110.5 & \pm 21.3 & $<150$ \\
TSH ( $\mu \mathrm{IU} / \mathrm{ml})$ & 1.44 & \pm 0.8 & $0.4-4.0$ \\
Progesterone* (ng/ml) & 11.8 & \pm 3.5 & $>5.0$ \\
\hline
\end{tabular}

SD: standard deviation, BMI: body mass index, LDL: low density lipoprotein, HDL: high density lipoprotein, TSH: thyroid stimulating hormone. *Collected on the 21st day of the menstrual cycle

Table 2. Hormone levels during the follicular, ovulatory, and luteal phases

\begin{tabular}{lccc}
\hline Variable & Follicular phase & Ovulatory phase & Luteal phase \\
\hline Estradiol $^{*}(\mathrm{pg} / \mathrm{ml})$ & $28.8 \pm 8.2^{\mathrm{a}, \mathrm{b}}$ & $219.4 \pm 91.3^{\mathrm{a}, \mathrm{c}}$ & $160.8 \pm 35.4^{\mathrm{b}, \mathrm{c}}$ \\
Total testosterone* $(\mathrm{ng} / \mathrm{dl})$ & $15.9 \pm 4.7^{\mathrm{a}, \mathrm{b}}$ & $36.4 \pm 4.2^{\mathrm{a}, \mathrm{c}}$ & $27.1 \pm 1.8^{\mathrm{b}, \mathrm{c}}$ \\
\hline${ }^{*} \mathrm{p}<0.05$ by the Kruskall-Wallis and Dunn post tests. ${ }^{\mathrm{a}, \mathrm{b}, \mathrm{c}}$ Averages with the same letter are statisti- \\
cally different
\end{tabular}

Table 3. Muscle tone and maximum voluntary contraction (MVC) in different phases of the menstrual cycle for women in menacme

\begin{tabular}{lccl}
\hline & Follicular phase & Ovulatory phase & Luteal phase \\
\hline Tone* $(\mu \mathrm{V})$ & $21.1 \pm 3.3 \mu \mathrm{V}^{\mathrm{a}}$ & $27.1 \pm 5.9 \mu \mathrm{V}^{\mathrm{b}}$ & $30.4 \pm 4.1 \mu \mathrm{V}^{\mathrm{a}, \mathrm{b}}$ \\
$\mathrm{MVC}(\mu \mathrm{V})$ & $64.3 \pm 5.0 \mu \mathrm{V}$ & $64.5 \pm 7.2 \mu \mathrm{V}$ & $66.8 \pm 7.1 \mu \mathrm{V}$ \\
\hline
\end{tabular}

${ }^{*} \mathrm{p}<0.05$ by the Kruskall-Wallis and Dunn post tests. ${ }^{\mathrm{a}, \mathrm{b}, \mathrm{c}}$ Averages with the same letter are statistically different

cycle (Table 3 ).

The $\mathrm{E}_{2}$ level on the 7 th day of the cycle showed a strong positive correlation with muscle tone $(r=0.9 ; \mathrm{p}<0.0001)$ and $\operatorname{MVC}(r=0.8 ; \mathrm{p}<0.0001)$. The TT level on the 21 st day of the menstrual cycle showed a strong positive correlation with muscle tone $(r=0.8 ; \mathrm{p}<0.0001)$.

\section{DISCUSSION}

Through EMG analysis of the PFM surface, we were able to identify a significant difference in muscle tone across the course of the normal menstrual cycle of women in menacme. The EMG technique evaluates the electrical activity of muscle membranes excited by neuromuscular activation.
The International Continence Society recommends the use of EMG to evaluate the PFMs. In addition to its evaluative purposes $^{8,11)}$, EMG has been widely used in experimental clinical studies to investigate the results of rehabilitative treatments for various PFM dysfunctions ${ }^{12-15)}$ and to compare conservative treatment versus surgery ${ }^{16)}$. EMG has high interobserver reproducibility for evaluating the maximum work and tone of the PFMs in healthy women ${ }^{10,17,18)}$.

In this study, the EMG values representing muscle tone were higher during the luteal phase. Studies using dynamometry have shown a change in skeletal muscle force during the ovulatory phase ${ }^{19,20)}$. Sarwar et al. ${ }^{19)}$ evaluated the isometric force of the quadriceps muscles and thumb and finger flexion in young women during the three phases of the 
menstrual cycle. Comparing users $(n=10)$ and nonusers ( $n$ $=10$ ) of oral hormonal contraceptives (OHCs), they identified an $11 \%$ increase in muscle force in the non-OHC group during the ovulatory period. In a similar study, Bambaeichi et al. ${ }^{20)}$ evaluated the isometric muscular force of the quadriceps muscle in young women $(n=8)$ with regular menstrual cycles. They observed greater contractility of the quadriceps muscles during the ovulation phase.

Phillips et al. ${ }^{1)}$ measured the MVC of the abductor hip muscles and examined its association with the $\mathrm{E}_{2}$ level in athletic $(n=10)$ and sedentary $(n=12)$ women with regular menstrual cycles and in athletes using OHCs $(n=5)$. They observed statistically significant results for peak force during the follicular period for the three groups and suggested that the increase in force might stem from elevated estrogen levels during this phase. In contrast, our study found no difference in MVC for all menstrual cycle phases when evaluated using EMG.

We should emphasize that the EMG technique captures the electrical activity promoted by the recruitment of motor units; this technique does not evaluate muscle force per se. However, Enck has affirmed that there is a good correlation between the number of activated motor units and muscle force $^{21)}$. Meigal et al. studied the EMG characteristics of the biceps and triceps brachii in women with respect to the phases of the menstrual cycle ${ }^{22)}$. The authors found that the variables of EMG activity significantly decreased in the ovulation phase. It is important to note that none of these studies evaluated the PFMs.

In our study of the electrical activity of the PFMs and serum levels of $E_{2}$ and TT, we observed positive correlations between the TT level and the muscle tone and MVC on the 7th day of the menstrual cycle, and a moderate correlation between the $\mathrm{E}_{2}$ level and $\mathrm{MVC}$ on the 21st day of the cycle. Janse de Jonge et al. did not find a relationship between hormone levels ( $\mathrm{LH}, \mathrm{FSH}, \mathrm{E}_{2}$, and progesterone) and the muscle force of the quadriceps and hand flexion during the initial follicular phase, late follicular phase, or late luteal phase ${ }^{23}$. The authors concluded that fluctuations in hormones during the reproductive phase do not affect the characteristics of muscle contractility in women. In the skeletal muscle system, it is possible to find many TT and type $\alpha$ and $\beta$ estrogen receptors ${ }^{24,25)}$. The effects of these signaling molecules result in direct hormone action on a specific receptor, inducing the transcription of specific genes in the intracellular environment ${ }^{25,26)}$.

This investigation is designed to expose physiotherapists to a new perspective on PFM function, namely that the EMG activity of the PMF varies during the normal menstrual cycle. We suggest that the plan for physiotherapy care should be individualized for each patient and include standard physiotherapy interventions for any dysfunction condition, such as stress urinary incontinence ${ }^{27)}$, prolapse, or muscle weakness ${ }^{8)}$.

In conclusion, the results of this study show that women have better muscle tone during the luteal phase. This study was the first to evaluate the PFM using EMG during a normal menstrual cycle. The muscle tone and MVC were strongly correlated with estradiol level on the 7th day, and the muscle tone was correlated with TT level on the 21 st day of the cycle. This suggests that the hormonal fluctuations during the menstrual cycle can alter PFM performance. Additional research is needed to clarify the exact relationship between sex hormones and PFM activity, including specific hormone receptors and the quantity of these receptors.

\section{REFERENCES}

1) Phillips SK, Sanderson AG, Birch K, et al.: Changes in maximal voluntary force of human adductor pollicis muscle during the menstrual cycle. J Physiol, 1996, 496: 551-557. [Medline] [CrossRef]

2) Lemoine $S$, Granier P, Tiffoche $C$, et al.: Estrogen receptor alpha mRNA in human skeletal muscles. Med Sci Sports Exerc, 2003, 35: 439-443. [Medline] [CrossRef]

3) Lee WJ, McClung J, Hand GA, et al.: Overload-induced androgen receptor expression in the aged rat hindlimb receiving nandrolone decanoate. $\mathrm{J}$ Appl Physiol 1985, 2003, 94: 1153-1161. [Medline] [CrossRef]

4) Ho MH, Bhatia NN, Bhasin S: Anabolic effects of androgens on muscles of female pelvic floor and lower urinary tract. Curr Opin Obstet Gynecol, 2004, 16: 405-409. [Medline] [CrossRef]

5) Silva WA, Karram MM: Anatomy and physiology of the pelvic floor. Minerva Ginecol, 2004, 56: 283-302. [Medline]

6) Talasz H, Himmer-Perschak G, Marth E, et al.: Evaluation of pelvic floo muscle function in a random group of adult women in Austria. Int Urogynecol J Pelvic Floor Dysfunct, 2008, 19: 131-135. [Medline] [CrossRef]

7) Nunes FR, Guirro EC, Martins CC, et al.: Influence of visual feedback on pelvic floor muscle strength. Eur J Obstet Gynecol Reprod Biol, 2010, 151: 217-220. [Medline] [CrossRef]

8) Kim BI, Hwang-Bo G, Kim HR: Comparison of abdominal muscle thickness with vaginal pressure changes in healthy women. J Phys Ther Sci, 2014, 26: 427-430. [Medline] [CrossRef]

9) World Health Organization: Obesity preventing and managing the global epidemic. Report of a WHO consultation on obesity. Geneva: WHO, 1997.

10) Grape HH, Dedering A, Jonasson AF: Retest reliability of surface electromyography on the pelvic floor muscles. Neurourol Urodyn, 2009, 28: 395-399. [Medline] [CrossRef]

11) Bordeianou L, Savitt L, Dursun A: Measurements of pelvic floor dyssynergia: which test result matters? Dis Colon Rectum, 2011, 54: 60-65. [Medline] [CrossRef]

12) Resende AP, Stüpp L, Bernardes BT, et al.: Can hypopressive exercises provide additional benefits to pelvic floor muscle training in women with pelvic organ prolapse? Neurourol Urodyn, 2012, 31: 121-125. [Medline] [CrossRef]

13) Resende AP, Zanetti MR, Petricelli CD, et al.: Effects of the Paula method in electromyographic activation of the pelvic floor: a comparative study. Int Urogynecol J Pelvic Floor Dysfunct, 2011, 22: 677-680. [Medline] [CrossRef]

14) Kaya $S$, Akbayrak T, Beksaç S: Comparison of different treatment protocols in the treatment of idiopathic detrusor overactivity: a randomized controlled trial. Clin Rehabil, 2011, 25: 327-338. [Medline] [CrossRef]

15) Piassarolli VP, Hardy E, Andrade NF, et al.: [Pelvic floor muscle training in female sexual dysfunctions]. Rev Bras Ginecol Obstet, 2010, 32: 234-240. [Medline]

16) Faried M, El Nakeeb A, Youssef M, et al.: Comparative study between surgical and non-surgical treatment of anismus in patients with symptoms of obstructed defecation: a prospective randomized study. J Gastrointest Surg, 2010, 14: 1235-1243. [Medline] [CrossRef]

17) Deffieux $X$, Hubeaux K, Porcher R, et al.: Pelvic floor muscle activity during coughing: altered pattern in women with stress urinary incontinence. Urology, 2007, 70: 443-447, discussion 447-448. [Medline] [CrossRef]

18) Auchincloss CC, McLean L: The reliability of surface EMG recorded from the pelvic floor muscles. J Neurosci Methods, 2009, 182: 85-96. [Medline] [CrossRef]

19) Sarwar R, Niclos BB, Rutherford OM: Changes in muscle strength, relaxation rate and fatiguability during the human menstrual cycle. J Physiol, 1996, 493: 267-272. [Medline] [CrossRef]

20) Bambaeichi E, Reilly T, Cable NT, et al.: The isolated and combined effects of menstrual cycle phase and time-of-day on muscle strength of eumenorrheic females. Chronobiol Int, 2004, 21: 645-660. [Medline] [CrossRef]

21) Enck P, Vodusek DB: Electromyography of pelvic floor muscles. J Electromyogr Kinesiol, 2006, 16: 568-577. [Medline] [CrossRef]

22) Mergal AI, Voronova NV, Elaeva LE, et al.: [EMG characteristics of women in respect with phase of the menstrual cycle, season and type of vegetative regulation]. Fiziol Cheloveka, 2014, 40: 113-121. [Medline] 
23) Janse de Jonge XA, Boot CR, Thom JM, et al.: The influence of menstrual cycle phase on skeletal muscle contractile characteristics in humans. J Physiol, 2001, 530: 161-166. [Medline] [CrossRef]

24) Wiik A, Ekman M, Johansson O, et al.: Expression of both oestrogen receptor alpha and beta in human skeletal muscle tissue. Histochem Cell Biol, 2009, 131: 181-189. [Medline] [CrossRef]

25) Vingren JL, Kraemer WJ, Ratamess NA, et al.: Testosterone physiology in resistance exercise and training: the up-stream regulatory elements. Sports Med, 2010, 40: 1037-1053. [Medline] [CrossRef]

26) Gustafsson JA: Novel aspects of estrogen action. J Soc Gynecol Investig, 2000, 7: S8-S9. [Medline] [CrossRef]

27) Ghaderi F, Oskouei AE: Physiotherapy for women with stress urinary incontinence: a review article. J Phys Ther Sci, 2014, 26: 1493-1499. [Medline] [CrossRef] 